\title{
Gendered Sociocultural Structures and Africa's Quest for Development
}

\author{
Grace Reuben Etuk ${ }^{1}$, Ugo Samuel Bassey ${ }^{2}$ \& Ejukwa Osam ${ }^{1}$ \\ ${ }^{1}$ Department of Social Work, Faculty of Social Sciences, University of Calabar, Calabar, Nigeria \\ ${ }^{2}$ Department of Sociology, Faculty of Social Sciences, University of Calabar, Calabar, Nigeria \\ Correspondence: Grace Reuben Etuk, Department of Social Work, Faculty of Social Sciences, University of \\ Calabar, P. M. B. 1115, Calabar, Nigeria. E-mail: graycetuk@yahoo.com
}

\author{
Received: August 28, $2019 \quad$ Accepted: October 17, $2019 \quad$ Online Published: November 28, 2019 \\ doi:10.5539/jsd.v12n6p121 URL: https://doi.org/10.5539/jsd.v12n6p121
}

\begin{abstract}
The way gender interfaces with development is a concern that has occupied the attention of development planners and feminists for some time now. The impetus for this concern is the realization that a key component for achieving development in all its dimensions is the existence of gender equality. This explains why the United Nations' Millennium Development Goals of 2000 framed its third goal as "To promote gender equality and women empowerment"; and more recently in its Sustainable Development Goals of 2015, the fifth goal is "To achieve gender equality and empower all women and girls". Against this backdrop, therefore, this paper attempts to accentuate the extent of gender inequality that has persisted in Africa's social structures, and how it has so far affected development on the continent. Particular prominence is given to the ways gender inequality in Africa's social structures have functioned to keep the continent's development rate at a snail pace by crippling the extent of participation in the development process by women - the main victims of gender inequality. The issue of gender and its effects on Africa's social systems and subsequently the processes that will lead up the continent's development must be properly addressed if a highway is to be created for development to ride in Africa. Thus, among other recommendations, the paper advocates for gender mainstreaming in policies and programmes at country level on the continent.
\end{abstract}

Keywords: gender, development, women, sex, Africa

\section{Introduction}

The goal of development is one that is of utmost importance to every contemporary society. For this reason, different societies deploy whatever resource there is within their disposal, human and material, to ensure that this all-important goal is achieved. Africa's appetite to also arrive at the very shores of development has been quite voracious. The continent had wasted years under the shackles of colonialism, the major vehicle for the young continent's exploitations by the West (Imhonopi, Urim \& Iruonagbe, 2013). Colonialism and the exploitations that accompanied it added up to make Africa arrive late at the global stage and scheme of events. As for the human and material resources needed to develop the continent, they existed in abundance. However, most of the material resources were lost to the Europeans who scrambled for the continent, while scores upon scores of the continent's human resources were carted away by the same Europeans via the Trans-Atlantic Slave Trade.

Upon breaking out of the hold of colonialism, the continent was ready to make its voice heard among the comity of nations, thus the journey to becoming developed began. Amidst various efforts aimed at achieving its goal of becoming a developed continent, Africa has been grappling with many daunting challenges, one of which is the gender inequality.

The African society is one that is still comparatively strict with the enforcement of gender, and the resultant inequalities make the playing field uneven for Africa's male and female human resources to participate in development. Unfortunately, women are the disadvantaged group in this uneven playing field.

Aina, (2012) carefully warned that gender issues are not same as women issues. As such, the concern here is not women and their place in Africa's development. Rather, the worry is about how fair and equitable the gendered social institutions and structures are to women compared to men in providing them with platforms to contribute to development. In the case of women, they are boxed in and given very limited opportunities to participate in 
development, but for the men, their opportunities are unlimited. As such, the bulk of Africa's development, over the decades, proceeded from men, with women contributing comparatively very skeletally. This means lost decades of developmental feats that would have come from women, had the social structures and institutions in the continent not been "genderized". The basis for this chapter, therefore, is to shed light on the gender issues that create danger issues for Africa's development.

\section{Conceptual and Theoretical Clarifications}

\subsection{Gender}

The term gender is often defined side by side with sex, its twin concept; and this is because the two concepts are closely linked. Both function to define how individuals perceive themselves, as well as how they are perceived by others. Above all, sex paves the way for individuals to tow a particular gender direction, while gender only finds expression when sex is clearly defined. What then is the dividing line between sex and gender?

Sex is the biological categorization of individuals as males and females to reflect their chromosomal differences. Gender, on the other hand, means the expectations, behaviors and attitudes prescribed for individuals as males and as females in society. Whereas sex is a biological phenomenon, gender is strictly a societal and cultural creation. As such, an individual is born a particular sex as male or female, but expresses gender based strictly on societal or cultural dictates.

Different societies have their definitions of what it means to be a male or female. For instance, Koch, Schey and Thimm (2003), based on their studies, listed out what many societies consider as the definition of being female to include: being empathic, cooperative, friendly, less assertive, with more communicative competence than men. On the other hand, they found the definition of being male to include: aggressiveness, assertiveness, analytical and being more logical. Based on such societal definition of maleness or masculinity and femaleness or feminity, different societies go on to prescribe expectations, behaviors and attitudes for each of the sexes. These expectations, behaviors and attitudes which societies prescribe for males and females in line with their definition of masculinity and feminity is what gender denotes. Thus, Abdul-Qadir (2005) aptly defines gender as the socially defined roles, attitudes and values which communities and societies ascribe as appropriate for one sex or the other.

As already highlighted, societies across the globe define being male as different from being female. It, therefore, follows that roles, behaviors and expectations prescribed for males and females would vary just the way their biological roles vary. This means that gender makes for variations in what men and women do, as well as when and how they do same in different societies. Gender role is the concept used in describing the varying obligations, roles and functions men and women are expected to fulfill in line with social and cultural prescriptions. Gender is thus responsible for the observed differences seen in nearly all societies in what men and women perform as their gender roles.

How society members become gendered, to the extent of clearly varying in their social roles, is an issue that has polarized the theoretical landscape in Sociology. A faction of sociologists known as sociobiologists argue firmly that becoming gendered is still a manifestation of the biological orientation of individuals. A notable scholar of this theoretical school namely Barash (1979) assert that men and women are biologically different with each pursing the maintenance of their genes in their own way. Thus, sociobiologists assert that 'biology is destiny' (Scarpitti \& Anderson, 1989), implying that all behaviors and roles of men and women in society are both natural and inevitable consequences of the biological differences present in the hormones, brains and other anatomical and genetic processes of the sexes.

On the other side of this theoretical debate are the Sociocultural Theorists, who are firm on the position that society and culture function jointly to make individuals become gendered, hence different societies vary in how their members express their gender. According to Haralambos and Heald, (1980), scholars of this theoretical school such as Ann Oakley, argue that human cultures which include social behaviors and gender roles emanate from the normative and value systems in society and not from invincible biological forces. Sociocultural Theorists insist that one tool utilized by society to get individuals to become gendered is socialization. Defined as the process of interaction by which people acquire the knowledge, attitudes, values and behaviors essential for effective participation in society (Hughes and Kroehler, 2005); socialization creates the platform for men and women to learn and adopt different roles and behavioral expectations in society. Thus, going by the sociocultural perspective, society, through the instrumentality of socialization, creates the avenue for individuals to become gendered as they learn and adopt the different roles and behavioral expectations specified for them by society. 


\subsection{Development}

Development is a complex, multifaceted and multidimensional phenomenon. It can be social, political, economic and even technological, yet more often, it is assessed only in terms of economic growth rates. However, economic growth rates measure only the economic dimension of development. Okolo (2007), citing the views of Nosike (1996), stated that development is about improving people's quality of life, and has issues like raising living standards and improving education, health and equality of opportunity as all constituting its essential components. Hence, Todaro and Smith (2009) suggested the concept be defined as the sustained elevation of an entire society and social system toward a better and more humane life.

According to Dickson (1985), cited in Etuk (2007), development is viewed as a universal goal, which makes it that all societies and nation states strive continuously to attain it. A number of countries, especially those in Europe and North America are considered to have attained development, hence their description as developed countries. Nevertheless, because of the crucial relevance of development, these countries continue to strive for more development. In Africa, and parts of Asia, a vast majority of countries are still considered as 'developing' and as such all their collective energies and resources are channeled towards attaining development. Why is development such a crucial issue? Abdulrahman (2005) provides the answers in pointing out that development makes for the eradication of poverty, illiteracy; facilitates the provision of basic needs such as nutrition, housing, water, electricity and transportation; guarantees the enjoyment of political freedom, human rights, personal self-respect; reduces inequality and makes for the retention of power to take part in the cultural and political life of the community.

For any society to attain or at least position itself on the path of attaining development, certain social factors and forces must be in operation. Going by the postulations of the Functional theory, society is a complex system whose component parts work together to promote its stability or balance. This theory stresses that the role of every part or component of society is needed to achieve social stability and solidarity. The theory, therefore, draws attention to the fact that if social stability in terms of development for instance must be achieved, the efforts of all the components of society including those of individuals, both males and females are needed. This implies that both men and women alongside other social institutions and structures are all key players in development processes. In the case of men and women, there is the problem of unequal opportunities to participate actively in development processes in society because of the phenomenon of gender; which typically stand for socially prescribed roles. That is to say, some roles are considered by society as 'unfeminine' and women are directly or indirectly restricted from taking them up, while limiting them to other roles which society views as 'feminine'. Similarly, some roles are considered by society as 'masculine' and as such they are seen primarily as the domain of men. This is the point gender interfaces with societal development. In the case of women, going by the Functional theory, the restrictions they face in taking up certain roles because they are 'unfeminine' have notable implications for development.

\section{Gender and Development: Facts and Policy Frameworks}

Several scholarly discourses have presented the subject of gender and development synonymously with women and development and vice versa. This is understandable considering that gender issues almost always center on women, since they are usually the disadvantaged group in the interplay of gender or power relations or in the event of gender inequality. However, the two subjects differ significantly from each other over the years, guided by feminist paradigms, development planners have formulated policy frameworks that address each of them. In the case of women and development, there are two policy models: the Women in Development (WID) Framework, and the Women and Development (WAD) Framework. Whereas the Women in Development (WID) addresses the need to integrate women into development, Women and Development (WAD) framework on the other hand, focuses on the interaction between women and all development processes.

In the case of gender and development, there are also two policy models. The first is the Gender in Development (GID) Framework, which emerged in the 1990s as gender statistics began to be widespread. The Gender in Development (GID) model explores gender inequalities in society and focuses on empowerment tools which target only women, although it does not address how gender relations contribute to the overall experience of women (Aina, 2012).

The Gender and Development (GAD) Approach, the policy framework of interest here is the second policy model that emerged to address issues pertaining to gender as it relates to development. The focal point of Gender and Development (GAD) framework is the socially and culturally constructed differences between men and women in society. GAD is concerned about existing gender roles and divisions and the need to confront them, considering that they subordinate women. 
The GAD policy framework was influenced mainly by the feministic writings of the British Sociologist Ann Oakley. As different from women in development and women and development, gender and development does not center attention only on women. It goes beyond women issues to how society prescribes and assigns roles, responsibilities and behavioral as well as attitudinal expectations to men and women, often to women's disadvantage. The GAD policy model draws attention to gender relations and gender division of labor in society and across cultures, and seeks to address issues of access to, as well as control of, available resources and power, both within the family and other public and privates spaces.

Gender and development seeks to ensure that both women and men participate in and benefit equally from development, and as such emphasizes equality of benefit and control (Muyoyeta, 2004). This is why the GAD policy framework aims at having gender roles and responsibilities redefined so that development outcomes would no longer be products of gendered social and economic processes.

\section{Impact of Gendered Sociocultural Structures on Africa's Quest for Development}

The whole idea of gender and development sheds light on the gendered nature of social structures and institutions, and questions how fair such systems are to women compared to men, when it comes to involvement in development processes. The question of gender and development stresses in clear terms that the 'genderized' social, political and economic institutions and structures in society make uneven the playing field for men and women as actors in development, with women being the disadvantaged group. Given that women are necessary actors in development processes, but yet disadvantageously positioned, unhealthy consequences are bound to follow. For Africa, the situation is even direr because most of the continent is still very traditional, with gender roles and relations very strict and clearly defined.

From the very point when the foundations for development were laid in Africa, the take-off structures were 'genderized'. The Europeans who colonized most of Africa set up educational institutions and developed curricular that emphasized domestic science for girls and technical as well as clerical skills boys (Rodney, 1973). This arrangement set the stage for, as well as prepared boys and girls to face society and then gendered their participation in development. In the case of girls, their education merely prepared them for roles of domestic nature, but for the boys they were prepared to explore and engage. Even after colonialism ended, African leaders merely continued with colonial legacies which lasted for decades. Thus, until recently around the dawn of the $21^{\text {st }}$ century, women were trailing way behind the men in issues regarding development in Africa because the very education that should have equipped them to be at par with men did otherwise. Ultimately, the continent lost decades of additional development strides that would have come from women, and depended only on what men who were equipped for the task could offer. And because the needed development was coming from just one segment of the population (men), Africa has remained down the ranks in development.

The problem of unequal opportunities for men and women to participate in Africa's development as a consequence of colonialism did not end only with the generation of individuals who were educated under the colonial educational system. It extended down the line. The Social Learning Theory by Bandura and Walters (1963) posits that individuals acquire roles by observational learning; meaning that younger persons can learn or adopt roles by just observing others, especially older persons of same sex. This theory brings to limelight the ripple effect colonial education would have had on how later generation of Africans, even those who received their education after colonialism, would come to be involved Africa's development process. The implication of Bandura and Walters' (1963) theory as discussed in Franzoi (1996) is that the post-colonial generation of young Africans had as their role models, as well as chose roles and careers by observing older men and women who had emerged as products of colonial education. Consequently, years after colonialism ended, Africa's development still continued to be short of adequate contribution from women because the younger generation had as their role models products of the colonial school system, who were prepared differently for development, with women being the disadvantaged group. Precisely, the women who became the role models for the later generations were the types who were trained only in domestic-related careers. However, the men who had better equipped role models automatically had better chances to contribute to development. As such, decades after colonialism, Africa's development landscape in terms of men and women's contribution was not very different from what it was during and shortly after colonialism, because the colonial generation reproduced themselves in those who would later man various development processes in the continent.

Long before and even after colonialism, one very gendered social structure in Africa that functioned and has continued to function to make for disparities between men and women in their contribution to development is gender division of labor in households. At the domestic sphere, gender division of labor places on women the responsibilities of performing housework or domestic labor as Humphrey (1987) describes it. House work refers 
to the cluster of duties performed in households and covers such activities as cooking, cleaning, washing, shopping as well as caring for children and the elderly. In her work 'The Sociology of Housework' Oakley (1979) pointed out that housework is stressful, tedious and time-consuming, occupying women for an average of seventy-seven hours per week. Seventy-seven hours per week means eleven hours of housework per day for an average woman. This raises serious concerns because as Etuk, Inyang and Etuk (2011) citing Haralambos and Heald (1980) noted, housework takes precedence over other roles as the primary role of women. If women would then have to give this role that occupies them for an average of eleven hours per day priority attention over every other role because it is their primary role, it means their chances of participating as adequately as men in development will face serious jeopardy. The logical conclusion from this is that on a daily basis, women will on the average be eleven hours behind in development processes, while men will remain ahead because they have the advantage of time. Gender division of labor in households is therefore contributing in no small measure in making women contribute less than men towards development and it is not wrong to conclude that this would have somewhat slowed the development pace of the African continent.

Besides occupying modern-day African women to the extent of leaving them with only little room to engage in development matters, housework prevented a number of African girls from even receiving whatever education that was available in the colonial era and even afterwards, while the boys had more opportunities. When the European missionaries introduced education, parents were usually worried about who would take care of house chores if the girls are sent off to school. For many parents, the opportunity cost of sending girls to school was considered to be high. As such, parents would rather send off the boys to school while leaving the girls at home to help out with housework. This made thousands or even millions of African girls not to be educated and equipped like the boys to take part in developing Africa, making the continent to also lose whatever development efforts that would have come from such women.

Patriarchy is another highly gendered social structure in Africa that has unfairly positioned women in development while favoring men. Patriarchy refers to a system of social structures and practices in which men dominate, oppress and exploit women (Walby, 1990) Africa is a highly patriarchal society; with social systems that promote male dominance, giving them advantage over women in many social issues. A practical example is in the area of leadership. The patriarchal system in Africa makes for the exclusion of women in many leadership positions. With the exception of Rwanda, leadership positions in African countries whether elective, traditional or appointive, are populated by men, with only dots of women in the elected and appointed positions. Traditional leadership positions are still almost exclusively the preserve of men. Being that leadership confers power and authority, it follows that with such power and authority men would also control other societal resources. By so doing, they put themselves ahead in matters that matter in society including development matters; leaving the women to trail behind. However, like a two-edged sword, such a trend goes on to rob Africa of women's contribution towards development by limiting their chances of using leadership positions to lend their voices in policy and decision making, the major vehicles for determining the direction of development.

Gender-based cultural practices namely early marriage and male-child preference, as well as the religious practice of women's seclusion (Purdah) among Muslims also ride on the wings of patriarchy to make participation in development not to be favorable to women.

Early marriage, a common practice in many parts of Africa such as in Sudan, Northern Nigeria, Niger, Tanzania, Malawi, Chad and Central Africa Republic, closes the door of education for many girls who are forced into the experience. With no more opportunities for education due to early marriage and the attending demands, the chances of such girls having a say in development are ruined, while the men on the other hand train as much as they would in preparation to earn a place in development processes. In fact, as Okolo (2003) emphasized, sometimes, the girls are even sent off to marry in order to raise money to educate their brothers. This ends up putting men ahead of women in development matters in all the parts of Africa where early marriage is an acceptable norm.

In the case of son or male-child preference, a widespread practice in Africa, it makes for men to be preferred in matters of land ownership and inheritance for instance. Inherited property and land are undeniably reliable sources of raising capital that can set an individual on the part of contributing hugely to development. With women not being favored in issues pertaining to land ownership and inheritance, the opportunities they would have had to ride on such platforms like the men to contribute to development are lost.

Purdah practice or women's seclusion in parts of Africa is another major factor to their subordination and male domination in efforts aimed at developing the continent. Many women who would have been resourceful actors in Africa's development are over the decades being secluded in the name of religion. Yet their male counterparts 
within their environments roam free. With a practice like this place, it is practically impossible for the women affected to come anywhere close to having same opportunities as men in such areas in matters relating to developing Africa.

Gender-based violence against women also works against their disposition to development oriented activities compared to men. Rape and spousal abuse for instance traumatize and expose women to various forms of health challenges, which many men do not have to face, being that they do not experience these forms of violence anywhere close to the degree women do. Time spent on hospital visits and recovery due to health problems resulting from these forms of violence will certainly keep the many women who were victims behind the men in contributing to development in the continent.

Lastly all socialization agencies, chiefly the family, have through differential socialization contributed to in weakening women's participation in development while strengthening men's involvement. From infancy, families in Africa socialize boys and girls differently. For example, girls are given dolls as toys while the boys get toy guns, cars robots, aircrafts and others. Playing with these toys provide the first platforms to rehearse their future roles. Later, their experiences with these toys also influence their choices of life goals, careers and disposition to development. Girls begin to prepare for marriage and childcare; and would likely limit their choices of social roles and careers to the ones that would give them room to marry and attend to issues relating to childcare and family life. On the other hand, the boys begin to look forward to operating in environments where they would be opportune to further interact with the objects they once played with as toys. Due to their toy exposure, therefore, boys often end up more relevant in crucial development issues than the girls. Moreover, the mere fact that they are socialized differently, in the case of women to take up 'feminine' roles and the men 'masculine' roles, makes it that they grow up incompetent in certain areas of social life. In the long run, their participation in development begins to reflect such incompetency. In the case of the women because feminine roles are often domestic, less challenging, passive and less assertive in nature, it also means that such would be the direction of their involvement in development. And in leaving the challenging, more assertive and adventurous tasks for the men, it becomes that men stay ahead of women in contributing to Africa's development.

\section{Conclusion and Recommendation}

Decades have rolled by since African countries embraced the idea of development and embarked on the mission of attaining it; and indeed various policies and programs have been channeled in this direction. Yet, only little progress has been made. Many African countries still rank among the least developed and a recognizable proportion of their populations still live in abject poverty; an obvious indication that development is still farfetched.

Clearly, gender inequality in the continent has contributed to Africa's development dilemma, by favoring women much less than men in terms of access to opportunities to participate in Africa's development processes. The effect of this has been that the burden of Africa's development has rested more or less on the shoulders of men alone. That is to say, all along, Africa's development equation has not been balanced, in that the development tasks meant for both men and women were all the while being undertaken mainly by men. As such, it could not have been possible for Africa to register more progress in development than what is currently on ground. There is, therefore, need to address the problem of gender and its attendant inequalities in African social structures and development processes. Steps that could make this possible at country level Africa would include:

- Commitment by governments to the United Nations' Sustainable Development Goals of ensuring gender equality and empowerment of women and girls.

- Embracing gender mainstreaming via the integration of gender perspectives in various government policies, and ensuring equal representation of men and women in the execution of policies and programs.

- Enactment of policies that will force existing gendered social structures to become as accommodating to women as they have been to men.

- Initiating and executing women empowerment programs to facilitate bringing them up to speed in participation in development processes.

- Organizing of reorientation programs aimed at helping women to become as assertive and proactive as the men.

Recently in 2018, some five Nigerian girls emerged the overall winners in the world Techonovation Challenge, by developing a mobile application called the FD-Detector to help tackle the problem of fake pharmaceutical 
products in Nigeria. This goes to show that more than ever before, African women are resolved to take on the challenge of lending a hand to the continent's development, to whatever level. To transform this resolve into results, the problem of gender inequality must be duly addressed so that women will have equal opportunities as men to adequately utilize their God-given abilities to facilitate the development of the African continent.

\section{References}

Abdul-Qadiri, U. A. (2005). Gender equity and reproductive health: Issues and challenges for sustainable development. In I. V. O. Modo (Ed.), Sustainable development in Africa: A book of readings (pp. 33-39). Uyo: Cultural Research Publishers,

Abdulrahman, D. (2005). Towards sustainable development in Nigeria. In I. V. O. Modo (Ed.), Sustainable development in Africa: A book of readings (pp. 33-39). Uyo: Cultural Research Publishers.

Aina, O. I. (2012). Two halves make a whole: Gender at the crossroads of Nigeria's development agenda. Ile-Ife Obafemi Awolowo University Press

Bandura, A., \& Walters, R. H. (1963). Social learning and personality development. New York: Holt, Rinehart and Winston.

Barash, D. (1979). The whisperings within. Haper and Row, New York

Etuk, G. R. (2007). Rural women and sustainable development in Nigeria. International Journal of Multidisciplinary Scholarship, 1(1), 30-37.

Etuk, G. R., Inyang, E. B., \& Etuk, R. U. (2011). Women's involvement level in housework and level of irregularities in public service: The need for gender sensitive changes in Nigeria's work policy. Review of Research and Social Intervention, 32, 95-106.

Franzoi, S. L. (1996). Social psychology. Brown and Benchmark, Madison.

Haralambos, M., \& Heald, R. M. (1980). Sociology: Themes and perspectives. Oxford: Oxford University Press.

Hughes, M., \& Kroehler, C. J. (1999). Sociology: The core. McGraw Hill College, New York.

Humphrey, J. (1987) Gender and work in the third world: Sexual division of labour in Brazilian industry. New York: Tavistock Publications.

Imhonopi, D., Urim, U. M., \& Iruonagbe, T. C. (2013). Colonialism, social structure and class formation: Implication for development in Nigeria. In D. Imhonopi, \& U. M. Urim (Eds.), A panoply of readings in social sciences: Lessons for and from Nigeria (pp. 107-122). Lagos: Department of Sociology, Covenant University, Ota, Ogun State.

Koch, S. C., Schey, S., \& Thimm, C. (2003) Communicating gendered: Competence, cooperation and conflict in the workplace. In J. Holmes, \& M. Meyerhoff (Eds.), The handbook of language and gender (pp.468-486). Oxford: Blackwell.

Muyoyeta, L. M. (2004). Women, gender and development, educating and acting for better world. Ireland.

Oakley, A. (1979). The sociology of housework. Oxford: Basil Blackwell.

Okolo, G. U. (2003). Violence against women. Calabar: Baye Communication.

Okolo, G. U. (2007). Culture, women and sociopolitical development in Nigeria. International Journal of Development and Management Review, 2(1), 80-87.

Rodney, W. (1973). How Europe underdeveloped Africa. Dar-Es-Salaam: Tanzanian Publishing House. Retrieved from http://www.marxists.org/subject/africa/rodney-walter/how-europe/ch01.htm

Scarpitti, \& Anderson. (1989). Social Problems. New York. Harper and Row.

Todaro, M. P., \& Smith, S. C. (2009). Economic development. London: Addison Wesley.

Walby, S. (1990). Theorizing patriarchy. Oxford: Blackwell.

\section{Copyrights}

Copyright for this article is retained by the author(s), with first publication rights granted to the journal.

This is an open-access article distributed under the terms and conditions of the Creative Commons Attribution license (http://creativecommons.org/licenses/by/4.0/). 